\title{
BMJ Open Attitude towards active surveillance: a cross-sectional survey among patients with uroandrological disorders
}

\author{
Paolo Capogrosso, ${ }^{1,2}$ Luca Boeri, ${ }^{1,2}$ Eugenio Ventimiglia, ${ }^{1,2}$ Ilenya Camozzi, ${ }^{3}$ \\ Walter Cazzaniga, ${ }^{1,2}$ Francesco Chierigo, ${ }^{1,2}$ Roberta Scano, ${ }^{2}$ Alberto Briganti, ${ }^{1,2}$ \\ Francesco Montorsi, ${ }^{1,2}$ Andrea Salonia ${ }^{1,2}$
}

To cite: Capogrosso P, Boeri L, Ventimiglia $\mathrm{E}$, et al. Attitude towards active surveillance: a cross-sectional survey among patients with uroandrological disorders. BMJ Open 2018:8:e022495. doi:10.1136/ bmjopen-2018-022495

- Prepublication history and additional material for this paper are available online. To view these files, please visit the journal online (http://dx.doi. org/10.1136/bmjopen-2018022495).

Received 24 February 2018

Revised 25 June 2018

Accepted 26 July 2018
Check for updates

(C) Author(s) (or their employer(s)) 2018. Re-use permitted under CC BY-NC. No commercial re-use. See rights and permissions. Published by BMJ.

${ }^{1}$ Urology, Università Vita-Salute San Raffaele, Milan, Italy ${ }^{2}$ Division of Experimental Oncology/Unit of Urology, URI, IRCCS Ospedale San Raffaele, Milano, Italy

${ }^{3}$ Department of Sociology and Social Research, University of Milano-Bicocca, Milan, Italy

Correspondence to Dr Paolo Capogrosso; paolo.capogrosso@gmail.com

\section{ABSTRACT}

Objectives We looked at subjective attitude towards active surveillance (AS) as the first option for cancer management in a cohort of patients seeking first medical help for uroandrological disorders prior to a formal discussion with a caregiver.

Design Cross-sectional observational study.

Setting Uroandrological outpatient clinic of a European academic centre.

Participants Data of 1059 patients at their first access for uroandrological purposes from January 2014 to December 2016 were analysed.

Intervention Patients were invited to complete a survey with closed questions investigating their attitude towards AS, prior to any clinical evaluation. Likewise, patients were invited to score the importance given to different aspects of personal life in the case of a cancer diagnosis, using a 10-point Likert scale.

Primary and secondary outcomes measures The reported opinion towards AS management for cancer was assessed. Logistic regression analyses tested participants sociodemographic characteristics associated with a positive opinion on AS.

Results Positive, negative and doubtful attitudes towards AS were observed in 347 (33\%), 331 (31\%) and 381 (36\%) patients, respectively. Female patients were more likely to report a negative attitude towards AS (38.7\% vs $29.6 \%$, $p=0.04$ ) while patients with previous parenthood more frequently reported a positive opinion on AS $(37.2 \%$ vs $29.9 \%$, $\mathrm{p}=0.005)$. Patient age emerged as the only predictor of a positive attitude towards AS (OR $1.03 ; 95 \% \mathrm{Cl} 1.01$ to 1.04 , $\mathrm{p}<0.001$ ), with a $46 \%$ and $33 \%$ probability of being pro-AS for a patient aged 65 and 45 years, respectively.

Conclusions One out of three patients would express positive feedbacks on AS in the unfortunate case of tumour diagnosis, only according to his/her baseline personal opinion and prior to any discussion with a cancer caregiver. The older the patient, the higher the probability of being compliant with a conservative management for cancer.

\section{INTRODUCTION}

The National Cancer Institutes dictionary of cancer terms defines active surveillance (AS) as a treatment plan involving a close watching of patient's condition based on regular examinations and tests, without

\section{Strengths and limitations of this study}

- Patients completed the survey before any interaction with a caregiver, thus providing unbiased information about their opinion on active surveillance (AS).

- We used a non-validated questionnaire to assess patients' opinion on AS, although the survey was developed with an expert in sociology and human behaviour

- The majority of patients were not assessed for cancer.

giving any active treatment unless there are changes in tests results demonstrating a worsening of the condition. ${ }^{1}$ This relatively novel attitude to approach and treat a patient gained increasing importance in the uro-oncological field throughout the last decades ${ }^{2-4}$; indeed, AS has emerged as a valid alternative to radical approaches for men with low-risk disease. ${ }^{56}$ Overall, patients with low-risk prostate cancer (PCa) currently managed with AS have been reported to range between $10 \%$ and $55 \% .{ }^{56}$ Likewise, AS for small renal masses is suggested as an available options by international clinical guidelines, ${ }^{3} 7$ although remains an uncommon practice, with data showing that only $9 \%-10 \%$ of cTla kidney cancer (KC) patients have been managed with AS in the last two decades. ${ }^{37}$

The rationale behind AS comes from the purpose to reduce the morbidity burden often associated with a potential overtreatment in subjects harbouring an indolent disease ${ }^{8}$; conversely, from their point of view, patients may consider irrational and dangerous not to treat a cancer, thus preferring a radical treatment to $\mathrm{AS} .{ }^{9}$

Numerous published surveys addressed the psychological aspects related to patients' acceptance and compliance to surveillance protocols for the primary management of cancer $^{9-14}$; psychological aspects including 
anxiety, distress, expectations and patients' personal attitude towards treatment options emerged to play a significant role over the decision-making process for cancer treatment. ${ }^{912}$ Available data on the psychosocial factors associated with patients' adherence to AS mainly come from self-selected cohorts of individuals already enrolled in AS protocols, ${ }^{121315}$ that could have been influenced by both their personal experience and the interaction with a caregiver. Indeed, also caregivers have a major impact on patients' final decision regarding cancer treatment modalities. ${ }^{15} 16$ Similarly, patients may have great concerns about the possibility to receive unbiased treatment recommendations. ${ }^{17}$

In order to provide data on the unbiased 'baseline' patients' perspective on AS as the primary treatment modality, we assessed a cohort of patients referring for the first time to the outpatient clinic of an academic centre for either benign or malignant uroandrological disorders, investigating their attitude towards the idea of AS in the unfortunate case of tumour diagnosis.

\section{METHODS}

The analyses were based on a cohort of 2069 consecutive patients (aged $\geq 18$ years) at their first access to a tertiary-referral outpatient clinic for uroandrological purposes from January 2014 to December 2016.

Participants were invited to complete anonymously an 8-item self-administered questionnaire with closed questions (online supplementary appendix 1). The questionnaire was developed in collaboration with an expert in sociology and human behaviour (IC).

As a prerequisite for entry, all participants were asked if they either regularly or at least occasionally surf the internet. In this context, terms and definitions that were used throughout the study have been taken from the internet, mainly considering blogs and forums for patients in order to consider terminology which could be readable and understandable for people who were not specifically in the medical field. To this aim, the concept of AS was not extensively explained prior to the survey compilation.

The survey included sections assessing sociodemographic aspects (questions 1-5 in online supplementary appendix 1 ) and their primary reason for the office visit (question 6 , online supplementary appendix 1 ). The attitude towards AS was investigated with a closed question (questions 7, online supplementary appendix 1): patients were asked whether, in the case of cancer diagnosis (for instance, prostate or kidney cancers), they would be willing to follow up the disease with examinations (including invasive tests, such as biopsy) over time, without treating it radically and immediately. Conversely, question 8 requested participants to subjectively score, with a 10-point Likert scale, the importance they would give to different aspects of life (thus including survival, partner and relationship, social life, personal belongings, sexual life, urinary continence and body image) in the same unfortunate case of tumour diagnosis.
Patients who refused to participate to the survey $(\mathrm{n}=831)$ and those who provided incomplete questionnaires $(n=228)$ were excluded from the analyses. Therefore, the final analysis considered a valid cohort of 1059 patients, reflecting a $51 \%$ response rate.

Data collection followed the principles outlined in the Declaration of Helsinki.

\section{Patient and public involvement}

Patients were not involved in the design and the development of the study.

\section{Statistical analyses}

The aim of the study was to assess the rate of patients reporting a positive attitude towards AS in a 'baseline' scenario. The association between patients sociodemographic characteristics and personal opinion on AS was also investigated; the statistical significance of differences between continuous and categorical variables was tested with the Wilcoxon rank-sum test, the one-way analysis of variance and Pearson $\chi^{2}$ test, accordingly.

Logistic regression analysis was used to test predictors of the attitude towards AS which was considered as a binary outcome (negative/doubtful vs positive). The adjusted probability of choosing AS was plotted on patient's age.

Statistical tests were performed using STATA V.13. All tests were two sided, with a significance level set at 0.05 .

Table 1 Sociodemographic characteristics of the entire cohort $(n=1059)$

\begin{tabular}{lc}
\hline Age, median (IQR) & $40(33-55)$ \\
Gender, n (\%) & $868(82)$ \\
Male & $191(18)$ \\
Female & \\
\hline Education status, $\mathrm{n}(\%)$ & $114(11)$ \\
\hline LL & $945(89)$ \\
HL & $909(86)$ \\
\hline Stable relationship, $\mathrm{n}(\%)$ & \\
\hline Previous parenthood, $\mathrm{n}(\%)$ & $414(39)$ \\
\hline Yes & $645(61)$ \\
\hline No & \\
\hline Primary reason for office visit, $\mathrm{n}(\%)$ & $295(28)$ \\
\hline Couple infertility & $212(20)$ \\
\hline Sexual dysfunction & $227(21)$ \\
\hline LUTS & $8(0.8)$ \\
\hline Urinary incontinence & $75(7.1)$ \\
\hline rUTls & $53(5)$ \\
\hline Urological cancer & $189(18)$ \\
\hline Other/uroandrological check-up & \\
\hline
\end{tabular}

HL, high educational level; LL, loweducational level; LUTS, lower urinary tract symptoms; rUTIs, recurrent urinary tract infections. 
Table 2 Participants' personal attitudes towards active surveillance (AS) management

\begin{tabular}{|c|c|c|c|c|}
\hline & \multicolumn{4}{|c|}{$\begin{array}{l}\text { Question 7-online supplementary appendix } 1 \\
\text { AS }\end{array}$} \\
\hline & No & I don't know & Yes & P values* \\
\hline Age, median (IQR) & $40(33-54)$ & $39(32-50)$ & $45(35-59)$ & $<0.0001$ \\
\hline \multicolumn{5}{|l|}{ Gender, n (\%) } \\
\hline \multicolumn{5}{|l|}{ Education status, n (\%) } \\
\hline LL & $38(33.3)$ & $42(36.8)$ & $34(29.8)$ & 0.8 \\
\hline $\mathrm{HL}$ & $293(31)$ & $339(35.8)$ & $313(33.1)$ & \\
\hline Stable relationship & $293(32.2)$ & $320(35.2)$ & $296(32.5)$ & 0.2 \\
\hline \multicolumn{5}{|l|}{ Primary reason for office visit, n (\%) } \\
\hline Couple infertility & $96(32.5)$ & $110(37.2)$ & $89(30.1)$ & 0.4 \\
\hline Sexual dysfunction & $63(29.7)$ & $82(38.6)$ & 67 (31.6) & \\
\hline LUTS & $78(34.3)$ & $76(33.4)$ & $73(32.1)$ & \\
\hline Urinary incontinence & $4(50)$ & $1(12.5)$ & $3(37.5)$ & \\
\hline rUTIs & $20(26.6)$ & $30(40)$ & 25 (33.3) & \\
\hline Urological cancer & $14(26.4)$ & $13(24.5)$ & $26(49.1)$ & \\
\hline Other/uroandrological check-up & $56(29.6)$ & $69(36.5)$ & $64(33.8)$ & \\
\hline
\end{tabular}

${ }^{*} \mathrm{P}$ values according to the Pearson's $\mathrm{X}^{2}$ and Kruskal-Wallis test.

HL, high educational level; LL, low educational level; LUTS, lower urinary tract symptoms; rUTIs, recurrent urinary tract infections.

Table 3 Subjective importance given to personal life aspects according to different opinions towards active surveillance (AS) among male and female patients

Question 8-online supplementary appendix 1

If you were diagnosed with cancer, how much importance would you give to different aspects of personal

life?

(Rate from $0=$ none to $10=$ highest importance)

Means (SD)

\begin{tabular}{|c|c|c|c|c|c|c|c|c|c|}
\hline & \multirow[b]{2}{*}{ Overall } & \multicolumn{3}{|c|}{ Male attitude towards AS } & \multirow[b]{2}{*}{ P values* } & \multicolumn{3}{|c|}{ Female attitude towards AS } & \multirow[b]{2}{*}{$P$ values' } \\
\hline & & Negative & Doubtful & Positive & & Negative & Doubtful & Positive & \\
\hline Survival & $9.4(1.5)$ & $9.5(1.3)$ & $9.4(1.6)$ & $9.3(1.7)$ & 0.7 & $9.5(1.3)$ & $9.4(1.6)$ & $9.3(1.7)$ & 0.2 \\
\hline $\begin{array}{l}\text { Friends and } \\
\text { relatives }\end{array}$ & $6.6(2.8)$ & $6.5(2.9)$ & $6.4(2.8)$ & $6.9(2.7)$ & 0.1 & $6.5(2.9)$ & $6.4(2.8)$ & $6.9(2.7)$ & 0.1 \\
\hline Sexual life & $6.6(2.8)$ & $6.5(2.8)$ & $6.6(2.7)$ & $6.8(2.8)$ & 0.4 & $6.5(2.8)$ & $6.6(2.7)$ & $6.8(2.8)$ & 0.3 \\
\hline $\begin{array}{l}\text { Urinary } \\
\text { continence }\end{array}$ & $7.1(2.8)$ & $7.3(2.9)$ & $6.9(2.8)$ & $7.1(2.8)$ & 0.7 & $7.3(2.9)$ & $6.9(2.8)$ & $7.1(2.8)$ & 0.3 \\
\hline
\end{tabular}

*Significance for differences within groups according to one-way analysis of variance test. 
Table 4 Logistic regression analysis predicting positive attitude towards active surveillance

\begin{tabular}{ll}
\hline & OR $(95 \%$ Cl) P values \\
\hline Age & $1.03(1.01$ to 1.04$)<0.0001$ \\
$\begin{array}{l}\text { Gender } \\
\text { (Male vs female) }\end{array}$ & $1.00(0.69$ to 1.43$) 1$ \\
$\begin{array}{l}\text { Education level } \\
\text { (LL vs HL) }\end{array}$ & $1.45(0.93$ to 2.26$) 0.1$ \\
$\begin{array}{l}\text { Stable marital relationship } \\
\text { Previous parenthood }\end{array}$ & $0.77(0.52$ to 1.13$) 0.2$ \\
$\begin{array}{l}\text { Primary reason for office } \\
\text { evaluation } \\
\text { (Other (any type) vs cancer) }\end{array}$ & $0.84(0.58$ to 1.21$) 0.3$ \\
\hline
\end{tabular}

$\mathrm{HL}$, higheducational level; LL, low educational level.

\section{RESULTS}

The sociodemographic characteristics of the entire cohort are reported in table 1; median age of participants was 40 years (IQR: 33-55). Main primary reasons for office evaluation were lower urinary tract symptoms (LUTS) in $21 \%$ (227) of cases and couple infertility reported by $28 \%$ (295) of cases. Of note, only 5\% (53) of the whole cohort presented for cancer evaluation.

Overall, 33\% (347) of the participants expressed a positive attitude towards AS (table 2). Patients with a positive feeling towards AS were significantly older compared with the others (table 2). Moreover, female patients were more likely to report a negative attitude towards conservative management for cancer as compared with male individuals $(38.7 \%$ vs $29.6 \%, \mathrm{p}=0.04)$, while those with previous parenthood more frequently reported a positive opinion on AS (37.2\% vs $29.9 \%, \mathrm{p}=0.005$ ) (table 2). Patients presenting for cancer evaluation did not report different attitudes towards AS compared with those presenting for non-oncological purposes (table 2).

Table 3 depicts self-reported scores given to the different aspects of life, after the hypothetical case of diagnosis of a

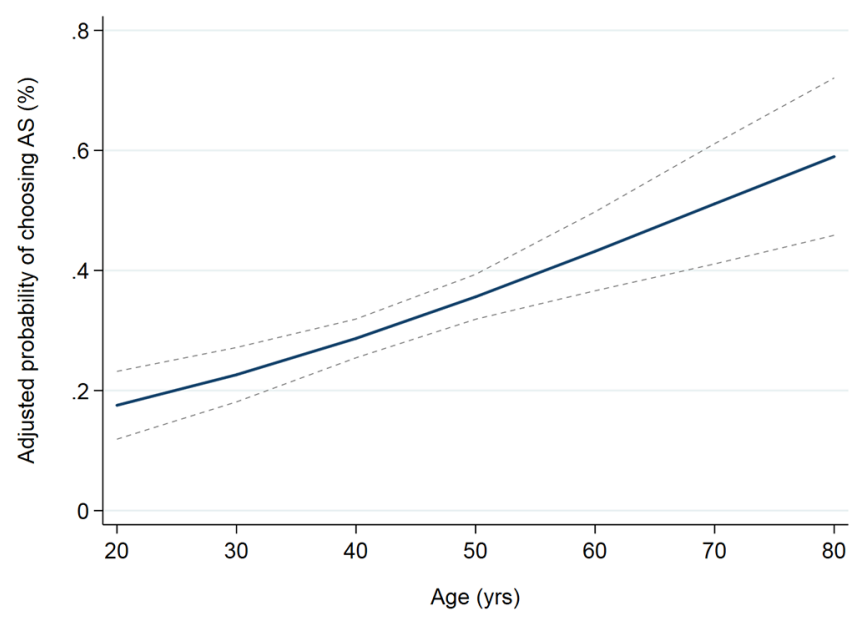

Figure 1 Adjusted probability of reporting a positive attitude towards active surveillance (AS) according to patients' age (dashed lines indicate the $95 \% \mathrm{Cl}$ values). cancer, according to gender. Overall, all patients attributed the highest importance to survival. No significant difference has been observed in terms of patients attitude towards AS for each category, but for social life to which both male and female patients with positive attitude to AS has been given greater importance $(\mathrm{p}<0.04)$.

At multivariable logistic regression analyses, age was positively associated with being pro-AS (OR 1.03, 95\% CI 1.01 to $1.04, \mathrm{p}<0.001)$, after adjusting for other sociodemographic characteristics (table 4). Figure 1 shows the adjusted probability of reporting a positive attitude towards AS according to patients' age; for those aged 65 years old, the probability of complying with AS for cancer management was $46 \%$ compared with $33 \%$ for patients aged 45 years.

\section{DISCUSSION}

We looked at the attitude towards AS among patients at their first clinical assessment for uroandrological disorders. We showed that one-third of them would choose AS management in the hypothetical unfortunate scenario of being diagnosed with a urological cancer, exclusively on the basis of their subjective opinion and without a previous discussion with a dedicated cancer caregiver. Female patients were less likely to be pro-AS for cancer management, while patients with children reported a positive attitude towards AS in a higher number of cases. Of note, patients age resulted as the only significant predictor of being pro-AS after accounting for other sociodemographic characteristics: older patients were significantly more likely to comply with AS in case of cancer diagnosis.

Patient's perspective and preferences play a major role over the cancer treatment decision-making process. ${ }^{8}$ Previous surveys assessed patients' preference towards different PCa treatments prior to the final therapeutic decision. $^{9-11}$ Zeliadt $e t$ al, for instance, reported a $15 \%$ rate of PCa patients willing to follow a watchful waiting approach mainly because of a number of concerns about the physical burden associated with active treatments. ${ }^{10}$ Moreover, de Bekker-Grob et al investigated treatment preferences in 110 patients undergoing biopsy for a suspicion of $\mathrm{PCa}$, before communicating the final diagnosis; they reported that up to $76 \%$ of patients without anxiety/depression would choose AS. ${ }^{9}$ A common limitation of both previous studies was patients' direct involvement with having PCa, and the potential concomitant impact of a discussion with their caregivers on the same topic. In our study, we provided novel findings by assessing the opinion on cancer surveillance in a cohort of patients that never discussed the issue of curative treatments or AS with any caregiver, and who mostly were seeking medical help for benign disorders, thus providing a sort of 'baseline' attitude of uroandrological patients towards living with an indolent cancer; our findings suggest that about $30 \%$ of patients would be willing to choose a surveillance management in case of cancer diagnosis, even before discussing the harms and benefit of this approach with a physician.

The relevant influence of a caregiver throughout the oncological decision-making process has been previously 
reported ${ }^{151618}$; in this context, adequate communication and patient education have been shown to have a positive effect in reducing anxiety and uncertainty related to therapeutic decisions. ${ }^{18}$ Recently, Ehdaie et al ${ }^{16}$ reported that a systematic approach for counselling PCa patients regarding AS led to an increase in terms of AS acceptance from $69 \%$ to $81 \%$ of cases. This would support our findings showing a $36 \%$ of patients doubting about being either pro or con AS, though not rejecting a priori the idea of choosing AS to finally manage their cancer.

The reasons behind patients' treatment preferences have been previously investigated; Hoffman et al reported that in a cohort of 934 men with PCa, almost $30 \%$ of those who had receive either surgery or radiotherapy eventually expressed treatment decision regret due to worse bowel and sexual outcomes. ${ }^{19}$ Previous data showed that the desire for cancer eradication is greater in younger patients, ${ }^{20}$ despite young persons could be also more prone to attempt and avoid functional side effects (ie, sexual dysfunction and urinary incontinence in the case of $\mathrm{PCa}$ ) potentially associated with active treatment. ${ }^{21}{ }^{22}$ In a cohort of 986 men below the age of 50 years and a diagnosis of low risk PCa, Sidana et al reported that surgery and AS were the preferred type of treatment in $81.4 \%$ and $5.3 \%$ of cases, respectively; moreover, physicians recommended against AS in more than $75 \%$ of cases. ${ }^{20} \mathrm{In}$ our series, we observed that patients who would choose AS were more likely to give high importance to social life in the case of cancer diagnosis; these results may be related to the fear for potential drawbacks associated with radical treatments that could impair the social life of the subject. Moreover, in line with previous data, we observed that the older the patient the higher the probability of reporting a positive attitude towards AS, regardless both their educational and family status; the odds of accepting either AS could be roughly $30 \%$ in a 45 -year-old patient, while they increased up to $46 \%$ for a patient aged 65 years. These results encourage physicians to comprehensively discuss cancer surveillance with younger patients who might be less inclined to accept this type of management, thus stressing the importance of a proper counselling aimed to improve the value of patients understanding and consciousness about treatment options, by giving a reliable estimation of the risks and side effects associated with both surveillance protocols and active treatments, both in oncological and functional terms. In this context, to further stress the relevance of a fruitful interaction with the patients, every physician should provide the outcomes of the treating centre along with those published across the scientific literature, thus to limiting and avoid false expectations.

This study is not devoid of limitations. First, we used a non-validated questionnaire to assess patients' opinion on AS. However, to the best of our knowledge, there are no currently available questionnaires specifically investigating all the aspects we have tried to assess. Second, although we obtained virtually 'unbiased' baseline opinions on AS of a homogenous cohort of uroandrological patients, more than one-third of the whole sample underwent primary evaluation for andrological conditions, thus raising the suspicion to pay more attention to quality-of-life issues than a population of oncological patients. To control for this specific bias, we analysed data from patients with a diagnosis of cancer within our cohort without finding any difference in terms of attitudes towards AS compared with non-cancer patients; moreover, seeking medical help for cancer was not associated with a specific attitude towards AS at multivariable analyses. Third, mean age in our setting was relatively lower compared with the usual age of $\mathrm{PCa}$ and $\mathrm{KC}$ populations; this aspect may even strengthen our results since we provided novel findings about patients' opinion on AS in a relatively young population, thus encouraging physicians to discuss surveillance management even in younger patients with cancer diagnosis in the everyday clinical setting. Fourth, given the specific nature of the enrolled population (ie, patients seeking medical help at an uroandrological outpatient clinic), we were not able to balance our cohort according to gender. However, a $20 \%$ of female subjects participated to the survey and we observed a significant difference in the opinion towards AS according to gender, thus suggesting that an adequate number of female patients had been included in the study. Fifth, we observed a relatively high rate of patients who refused to complete the survey, thus potentially introducing a further selection bias; however, we did not find any difference in terms of sociodemographic characteristics between patients who complete and those who did not complete the survey at a sensitivity analysis (all $\mathrm{p}>0.05$ ). Last, we lack any specific tool to evaluate psychological distress almost inevitably associated with being diagnosed with a cancer, and even more relevant with a cancer for which available therapies are potentially associated with a number of persistent complications interfering with both sexual and urinary functions.

\section{CONCLUSIONS}

We provided novel evidence that about one-third of patients would opt for AS in the unfortunate case of tumour diagnosis before any interaction with a cancer caregiver, with as many as one-third of the questioned patients sample completely doubtful about the choice. Of clinical relevance, the older the patient, the higher the probability of choosing a conservative management for cancer. Physicians should be encouraged to keep suggesting AS to old patients when clinically appropriate and to comprehensively discuss the adequacy of a conservative cancer management with younger individuals to improve their subjective acceptability, and the consequent compliance, towards this type of treatment.

Contributors PC and AS conceived and designed the study. LB, WC, RS and FC collected the data. IC and AS developed the questionnaire. PC and EV conducted the analysis. FM, $A B$ and $A S$ critically revised the manuscript for important intellectual content. All authors approved the final version prior to submission.

Funding The authors have not declared a specific grant for this research from any funding agency in the public, commercial or not-for-profit sectors. 
Competing interests None declared.

Patient consent Obtained.

Ethics approval IRCCS 0spedale San Raffaele.

Provenance and peer review Not commissioned; externally peer reviewed.

Data sharing statement The authors' licence for using these data precludes the sharing of raw data with third parties.

Open access This is an open access article distributed in accordance with the Creative Commons Attribution Non Commercial (CC BY-NC 4.0) license, which permits others to distribute, remix, adapt, build upon this work non-commercially, and license their derivative works on different terms, provided the original work is properly cited, appropriate credit is given, any changes made indicated, and the use is non-commercial. See: http:// creativecommons.org/licenses/by-nc/4.0/.

\section{REFERENCES}

1. National Cancer Institutes.. Dictionary of cancer terms;. https://www. cancer.gov/publications/dictionaries/cancer-terms?cdrid=616060.

2. Ritch CR, Graves AJ, Keegan KA, et al. Increasing use of observation among men at low risk for prostate cancer mortality. $J$ Urol 2015;193:801-6.

3. Huang WC, Atoria CL, Bjurlin M, et al. Management of small kidney cancers in the new millennium: contemporary trends and outcomes in a population-based cohort. JAMA Surg 2015;150:664-72.

4. Cooperberg MR, Broering JM, Carroll PR. Time trends and local variation in primary treatment of localized prostate cancer. $J$ Clin Oncol 2010;28:1117-23.

5. Hamdy FC, Donovan JL, Lane JA, et al. 10-year outcomes after monitoring, surgery, or radiotherapy for localized prostate cancer. $N$ Engl J Med 2016;375:1415-24.

6. Cooperberg MR, Carroll PR. Trends in management for patients with localized prostate cancer, 1990-2013. JAMA 2015;314:80-2.

7. Drangsholt S, Huang WC. Current trends in renal surgery and observation for small renal masses. Urol Clin North Am 2017:44:169-78.

8. Dall'Era MA. Patient and disease factors affecting the choice and adherence to active surveillance. Curr Opin Urol 2015;25:272-6.
9. de Bekker-Grob EW, Bliemer MC, Donkers B, et al. Patients' and urologists' preferences for prostate cancer treatment: a discrete choice experiment. Br J Cancer 2013;109:633-40.

10. Zeliadt SB, Moinpour CM, Blough DK, et al. Preliminary treatment considerations among men with newly diagnosed prostate cancer. Am J Manag Care 2010;16:e121-30.

11. Xu J, Dailey RK, Eggly S, et al. Men's perspectives on selecting their prostate cancer treatment. J Natl Med Assoc 2011;103:468-79.

12. van den Bergh RC, Essink-Bot ML, Roobol MJ, et al. Anxiety and distress during active surveillance for early prostate cancer. Cancer 2009;115:3868-78.

13. van Vugt HA, Roobol MJ, van der Poel HG, et al. Selecting men diagnosed with prostate cancer for active surveillance using a risk calculator: a prospective impact study. BJU Int 2012;110:180-7.

14. Hoffman RM, Van Den Eeden SK, Davis KM, et al. Decision-making processes among men with low-risk prostate cancer: a survey study. Psychooncology 2018;27.

15. Gorin MA, Soloway CT, Eldefrawy A, et al. Factors that influence patient enrollment in active surveillance for low-risk prostate cancer. Urology 2011;77:588-91.

16. Ehdaie $B$, Assel M, Benfante $N$, et al. A systematic approach to discussing active surveillance with patients with low-risk prostate cancer. Eur Urol 2017;71:866-71.

17. Albertsen PC, Hanley JA, Fine J. 20-year outcomes following conservative management of clinically localized prostate cancer. JAMA 2005;293:2095-101.

18. Pickles T, Ruether JD, Weir L, et al. Psychosocial barriers to active surveillance for the management of early prostate cancer and a strategy for increased acceptance. BJU Int 2007;100:544-51.

19. Hoffman RM, Lo M, Clark JA, et al. Treatment decision regret among long-term survivors of localized prostate cancer: results from the prostate cancer outcomes study. J Clin Oncol 2017;35:2306-14.

20. Sidana A, Hernandez DJ, Feng Z, et al. Treatment decision-making for localized prostate cancer: what younger men choose and why. Prostate 2012;72:58-64.

21. Tavlarides AM, Ames SC, Diehl NN, et al. Evaluation of the association of prostate cancer-specific anxiety with sexual function, depression and cancer aggressiveness in men 1 year following surgical treatment for localized prostate cancer. Psychooncology 2013;22:1328-35.

22. Salonia A, Adaikan G, Buvat J, et al. Sexual Rehabilitation After Treatment for Prostate Cancer-Part 1: Recommendations From the Fourth International Consultation for Sexual Medicine (ICSM 2015). J Sex Med 2017;14:285-96. 